\title{
BCCN4,
}

\section{HYBRID COMPOSITES BASED ON SILICA, GLASS AND SHORT SISAL FIBRES}

\author{
Bruna T. Ferreira ${ }^{(1)}$, Leandro J. Silva ${ }^{(1)}$, Túlio H. Panzera ${ }^{(1)}$, Júlio C. Santos ${ }^{(2)}$ and \\ Michael D. Naughton(3)
}

(1) Centre for Innovation and Technology in Composite Materials - CIT ${ }^{\mathrm{e}} \mathrm{C}$, Department of Mechanical Engineering, Federal University of São João del Rei - UFSJ, Brazil.

(2) Centre for Innovation and Technology in Composite Materials - CIT ${ }^{\mathrm{e}} \mathrm{C}$, Department of Natural Sciences, Federal University of São João del Rei - UFSJ, Brazil.

(3) Department of Mechanical and Automobile Engineering, Limerick Institute of Technology, Limerick, Ireland.

https://doi.org/10.21452/bccm4.2018.10.09

\begin{abstract}
Studies of composite materials in recent years have focused on the use of natural fibres as an alternative to synthetic fibres. The attractive mechanical properties, sustainability, low cost and low weight are potential factors that have leveraged research in this area, due to the variety of applications in the engineering sector. A full factorial design $\left(2^{1} 6^{1}\right)$ was performed to identify the effect of silica inclusions and the stacking sequence of glass fibres and short sisal fibres. The response-variables, such as apparent density, tensile and flexural strength and modulus of elasticity, were assessed in this work. In general, the incorporation of silica particles improved the performance of composites containing larger amounts of sisal fibres. Hybrid composites with higher number of glass fibre layers achieved higher values of tensile and flexural strength (348 MPa and 663.28 MPa) and tensile and flexural modulus (22 GPa and 2.50GPa) and higher apparent density value $\left(2.02 \mathrm{~g} / \mathrm{cm}^{3}\right)$.
\end{abstract}

\section{INTRODUCTION}

Natural fibre composite materials have been widely used because of their sustainable characteristics, moderate strength and low cost [1,2]. One way that has been studied as an alternative to reduce the use of synthetic fibres is through hybridization of these fibres with natural fibres [3,4]. Hybridization is when the material has more than one type of reinforcement, either in the form of fibres or particles [2]Hybridization of sisal and glass fibres has been proposed in the literature specially to reduce final costs of composite materials $[5,6]$. Moreover, another factor that significantly influences the mechanical properties of these composites is the form of stacking of the fibers [7], having great importance in the final properties of the material. Fiber-reinforced composites and micro-nanoparticles have been 
investigated specifically to increase the thermal stability and the specific mechanical properties of laminated composites [8,9]. According to Silva et al. [10], the particles intercept the propagation of cracks, this effect retards the growth of cracks in the hybrid composites increasing their mechanical properties and preventing catastrophic failure. The incorporation of particles into laminates can increase the stiffness of matrix phase, in addition to promoting an interlocking effect between laminates [8-9, 11].

The types of fibers and particles and their arrangement affect the compatibility and interaction of these elements with the phase of the polymer matrix, being considered determinants in the final property of the material [12].

The present work studies hybrid composites with different stacking sequences of glass and sisal fibers and also investigates the efficiency of the use of silica particles as another type of composite reinforcement. A full factorial design was conducted to identify the effect of the sisal-glass fibre stacking sequences and inclusions of silica microparticles on the physical and mechanical properties of compacted hybrid composites.

\section{MATERIALS AND METHODS}

\subsection{Materials}

The hybrid composites were fabricated with five layers of sisal/glass fibres via compression molding. Random sisal short fibres were supplied by Sisalsul Company (Brazil). A cross-ply glass fibre fabric of $200 \mathrm{~g} / \mathrm{cm}^{2}$ was used in the experiment. Renlam M epoxy resin and HY Aradur 951 hardener were supplied by Hunstman Brazil. The silica micro particles were sourced by Omega Mining Company (Brazil).

\subsection{Design of experiment}

A full factorial design $\left(2^{1} 6^{1}\right)$ was established to identify the effect of silica inclusions $(0$ and $5 \mathrm{wt} \%)$ and stacking sequence of short sisal fibres (S) and glass fibres (G) on the physical and mechanical properties of hybrid composites (see Table 1).

Table 1: Full Factorial Design $\left(2^{1} 6^{1}\right)$.

\begin{tabular}{ccc}
\hline Experimental Conditions & Layers Sisal/Glass & Silica inclusion (\%) \\
\hline 1 & $5 \mathrm{~S}$ & 0 \\
2 & $4 \mathrm{~S} / 1 \mathrm{G}$ & 0 \\
3 & $3 \mathrm{~S} / 2 \mathrm{G}$ & 0 \\
4 & $2 \mathrm{~S} / 3 \mathrm{G}$ & 0 \\
5 & $1 \mathrm{~S} / 4 \mathrm{G}$ & 0 \\
6 & $5 \mathrm{G}$ & 0 \\
7 & $5 \mathrm{~S}$ & 5 \\
8 & $4 \mathrm{~S} / 1 \mathrm{G}$ & 5 \\
9 & $3 \mathrm{~S} / 2 \mathrm{G}$ & 5 \\
10 & $2 \mathrm{~S} / 3 \mathrm{G}$ & 5 \\
11 & $1 \mathrm{~S} / 4 \mathrm{G}$ & 5 \\
12 & $5 \mathrm{G}$ & 5 \\
\hline
\end{tabular}

The

responses investigated in the experiment were apparent density, mechanical strength/modulus under tensile and flexural loads. Fifteen hybrid composite specimens ( 5 for physical tests, 5 for tensile, 5 for bending) were fabricated for each of the 12 experimental conditions. Two replicates were considered, running a total of 360 specimens. The replicate consists of the 
repetition of the experimental condition in order to estimate the experimental error of the individual response. A randomization procedure was adopted during sample manufacturing and experimental testing, avoiding uncontrolled factors from affecting responses [13]. Minitab 17 software was used to perform statistical analysis based on Design of Experiment (DoE) and Analysis of Variance (ANOVA).

\subsection{Manufacturing process}

The epoxy polymer was prepared by mixing the resin and the hardener at a ratio of 10:1 for 5 minutes. The particles were classified by sieving process in monomodal size of $0.037 \mathrm{~mm}$. Subsequently, the silica particles were added to the epoxy polymer and hand-mixed for 5 minutes at room temperature $\left(\sim 21^{\circ} \mathrm{C}\right)$. A fibre volume fraction of $20 \%$ was kept constant, being determined based on preliminary tests, in order to avoid resin leakage after compaction.

The composites were fabricated using a wood mould (200 x $200 \mathrm{~mm})$ and a cold uniaxial pressure of $0.75 \mathrm{MPa}$ for 12 hours. After 7 days curing, the plates were cut to size according to ASTM standards [14-15] (Figure 1). The sisal fibres were replaced by glass fibres from the bottom to the top surfaces as shown in Figure 2. Each layer of glass fibre fabric weighed $7.0 \mathrm{~g}$, while each layer of random sisal fibre weighed $3.4 \mathrm{~g}$.
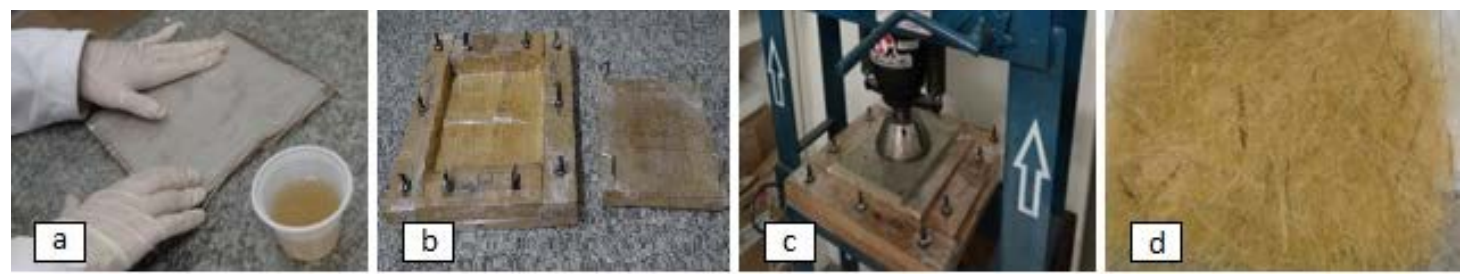

Figure 1: Manufacturing process of the hybrid composites: (a) lamination of the fibres, (b) wooden mould, (c) cold pressing, (d) material after compaction.

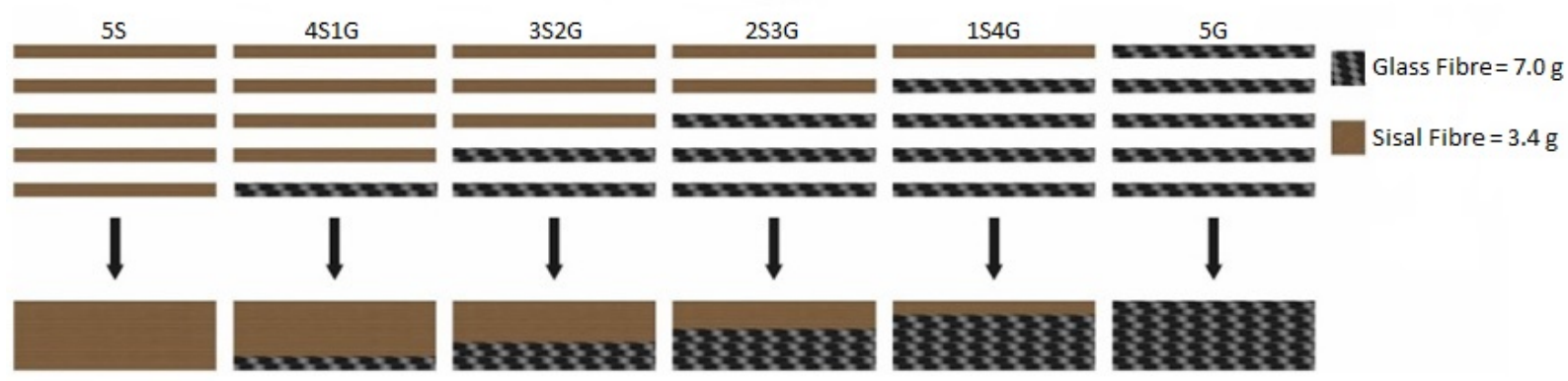

Figure 2: Stacking sequence of the fibres.

\subsection{Testing}

Tensile and flexural tests were carried out based on the recommendations of ASTM D303914 [14] and ASTM D790-15 [15], respectively. The Zwick /Roell Z020 test machine with a $20 \mathrm{kN}$ load cell was used to perform both tests, which were conducted at a test speed of 2 $\mathrm{mm} / \mathrm{min}$. The apparent density and apparent porosity were determined according to BS 105453 [16], based on the Archimedes principle using a precision balance (0.001g) and distilled water. 


\section{RESULTS}

Table 2 shows the analysis of variance (ANOVA). P-values less or equal to 0.05 indicate the individual factor or the interaction significantly affect the response. When one or more interaction effects of superior order are significant, the interacting factors can be considered together [17]. The underlined P-values shown in Table 2 significantly affected the responses. Pvalues in bold show the presence of interaction effects. $\mathrm{R}^{2}$ values close to $100 \%$ indicate that the model has higher predictive capacity [17]. To validate the ANOVA, a normality test (Anderson-Darling) was conducted based on the residual analysis for each response-variable. In this case, P-values must be greater than 0.05, as shown in Table 2.

Table 2. Analysis of Variance (ANOVA)

\begin{tabular}{|c|c|c|c|c|c|c|}
\hline \multirow{2}{*}{\multicolumn{2}{|c|}{$\begin{array}{r}\text { ANOVA } \\
\text { Experimental Factors }\end{array}$}} & \multicolumn{5}{|c|}{ P-value $\leq 0.05$} \\
\hline & & $\begin{array}{l}\text { Apparent } \\
\text { density } \\
\left(\mathrm{g} / \mathrm{cm}^{3}\right)\end{array}$ & $\begin{array}{l}\text { Tensile } \\
\text { Strength } \\
(\mathrm{MPa})\end{array}$ & $\begin{array}{l}\text { Tensile } \\
\text { Modulus } \\
(\mathrm{GPa})\end{array}$ & $\begin{array}{l}\text { Flexural } \\
\text { Strength } \\
(\mathrm{MPa})\end{array}$ & $\begin{array}{l}\text { Flexural } \\
\text { Modulus } \\
\text { (GPa) }\end{array}$ \\
\hline \multirow{2}{*}{ 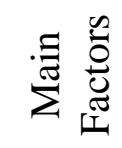 } & Silica Inclusion (SI) & 0.442 & $\underline{0.000}$ & 0.951 & $\underline{0.000}$ & $\underline{0.115}$ \\
\hline & Glass fibre inclusion (GFI) & $\underline{0.000}$ & $\underline{0.000}$ & $\underline{0.000}$ & $\underline{0.000}$ & $\underline{0.000}$ \\
\hline \multirow{2}{*}{ 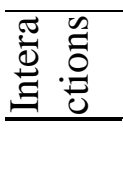 } & SI x GFI & 0.13 & $\underline{0.000}$ & 0.389 & $\underline{0.000}$ & $\underline{0.029}$ \\
\hline & $\mathrm{R}^{2}-$ adj & $99.13 \%$ & $98.63 \%$ & $98.49 \%$ & $98.68 \%$ & $98.28 \%$ \\
\hline \multicolumn{2}{|c|}{ Anderson-Darling (P-value $\geq 0.05$ ) } & 0.133 & 0.132 & 0.989 & 0.313 & 0.057 \\
\hline
\end{tabular}

\subsection{Apparent Density}

The apparent density of the composites ranged from $1.15 \mathrm{~g} / \mathrm{cm}^{3}$ to $2.02 \mathrm{~g} / \mathrm{cm}^{3}$. The elastic properties of the composites were not affected or reduced in the presence of silica particles (Table 2). The glass fibres promoted an increase in mean apparent density as shown in Figure 3 , due to their higher density relative to the sisal fibres. 


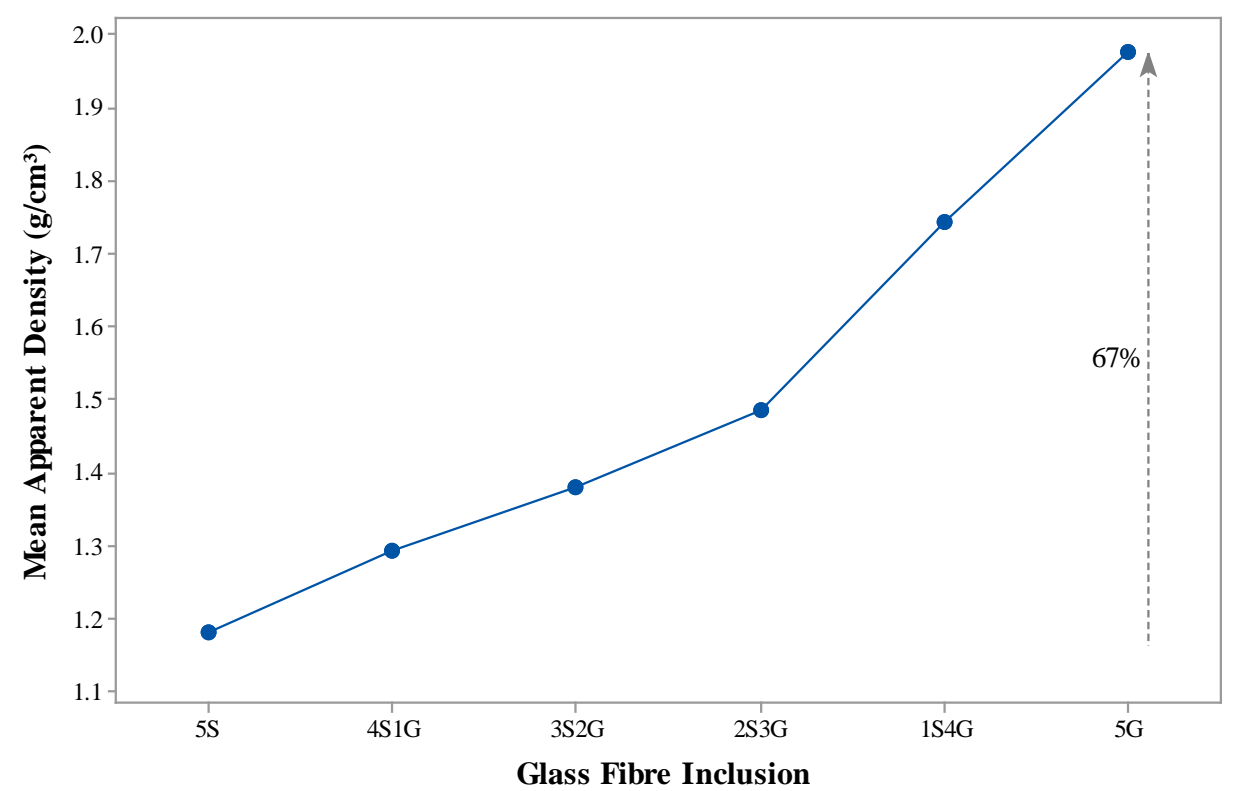

Figure 3. Main effect of glass fibre inclusions for mean apparent density of the composites

\subsection{Tensile Strength}

Figure 4 shows the interaction effect plot for mean tensile strength of the composites. The presence of silica led to reduced tensile strength values. This fact can be attributed to the nonefficiency of the particle-reinforced matrix under tensile load, followed by a possible reduction of interlaminar adhesiveness due to the silica incorporation. It was observed that the larger the amount of glass fibre, the greater the matrix phase volume expelled during the manufacturing process. Silica particles within laminated composites have a positive effect when the amount of matrix phase is maintained in the system [18]. As shown in Figure 4, tensile strength values are reduced when the amount of glass fibre layers is increased. This behaviour is related to the effect between the amount of matrix phase and silica particles. It is noteworthy that composites made with 4 layers of sisal and 1 of glass fibre (4S1G) without silica inclusions obtained an increase in tensile strength of $84 \%$ when compared to composites made with only natural fibres (5S). In contrast, significant percentage reductions were achieved when a glass fibre layer was replaced by the sisal fibre layer (1S4G), especially when no silica particle was added. 


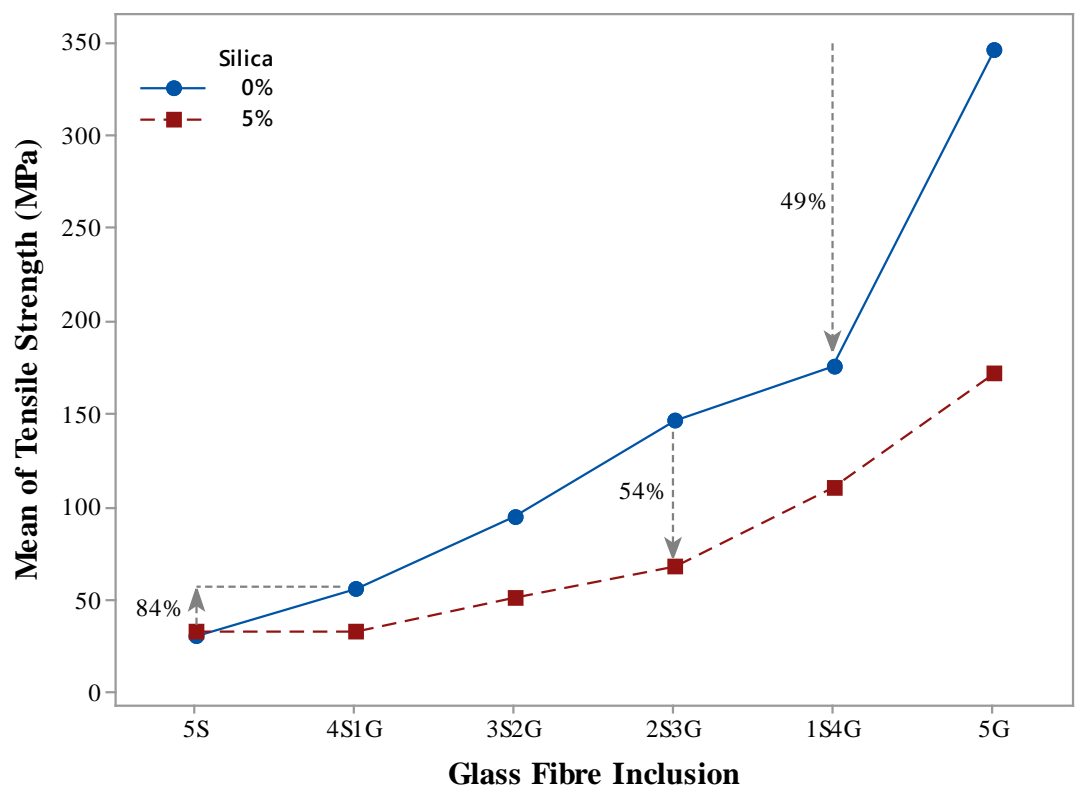

Figure 4. Interaction effect plot for mean tensile strength.

\subsection{Tensile Modulus}

Modulus of elasticity values ranged from $3.50 \mathrm{GPa}$ to $22.00 \mathrm{GPa}$. Figure 5 shows the main effect plot for glass fibre inclusion factor. The treatments containing larger amounts of glass fibre layers obtained a higher tensile modulus, leading to a substantial increase of $477 \%$ from 5S to 5G. This behaviour was expected, considering that glass fibres exhibit superior mechanical performance to natural fibres.

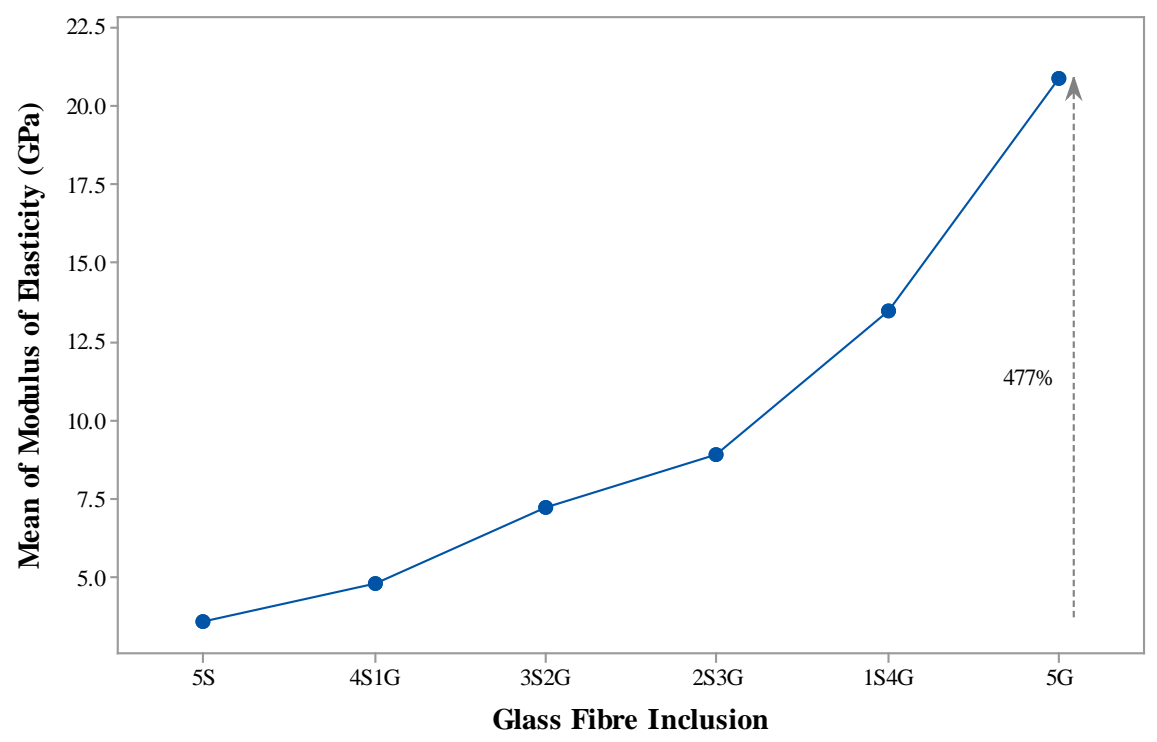

Figure 5. Main effect plot for mean modulus of elasticity.

\subsection{Flexural Strength}


Flexural strength values ranged from 51.36 MPa to $663.28 \mathrm{MPa}$. Figure 6 shows the interaction effect plot for mean flexural strength. The inclusion of particles led to reduced strength, except for composites made with $100 \%$ sisal fibres. The presence of silica particles provided a significant reduction $(\sim 30 \%)$ in the flexural strength of glass fibre reinforced composites (5G). A significant reduction was also observed when the glass fibres were replaced by one or more layers of sisal fibre. Otherwise, 2S3G composites without particles reached a percentage increase of $407 \%$ when compared to composites reinforced with sisal fibres (5S). The reduction of $25 \%$ in the $1 \mathrm{~S} 4 \mathrm{G}$ condition can be explained by the fact that the sisal fibres used in the upper part of the composite are short and arranged randomly in the matrix, which implies the possibility of the existence of regions without the presence of fibres reinforcement.

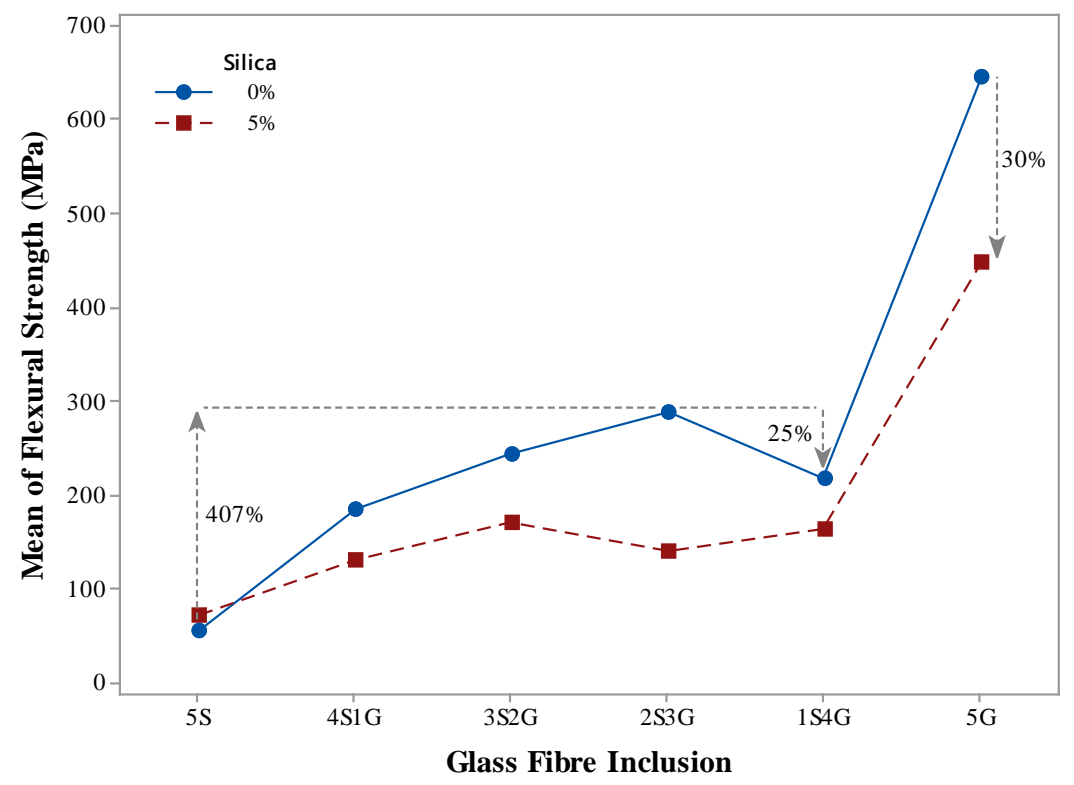

Figure 6. Interaction effect plot for mean flexural strength.

\subsection{Flexural Modulus}

The flexural modulus values varied between $1.61 \mathrm{GPa}$ and $2.50 \mathrm{GPa}$. Figure 7 shows the interaction effect plot for mean flexural modulus. The highest flexural modulus was achieved when the composites were fabricated using five layers of glass fibre (5G) without silica inclusion. Silica particles promoted a positive effect only when a greater amount of sisal fibres was considered (5S and 4S1G). This behaviour suggests that the particles contribute more effectively to increase the matrix phase stiffness rather than the interlocking effect. In addition, the use of short random sisal fibres can lead to internal regions without fibre reinforcement, consequently, the particles can provide a mutually beneficial effect, increasing matrix phase stiffness and filling voids. A significant reduction ( 70\%) in the flexural modulus was evidenced when only a single layer of glass fibres (1S4G) was replaced by sisal. It is noteworthy that a significant increase of approximately $324 \%$ in stiffness was achieved, compared to $5 \mathrm{~S}$ composites, when three layers of glass fibre (2S3G) were incorporated. 


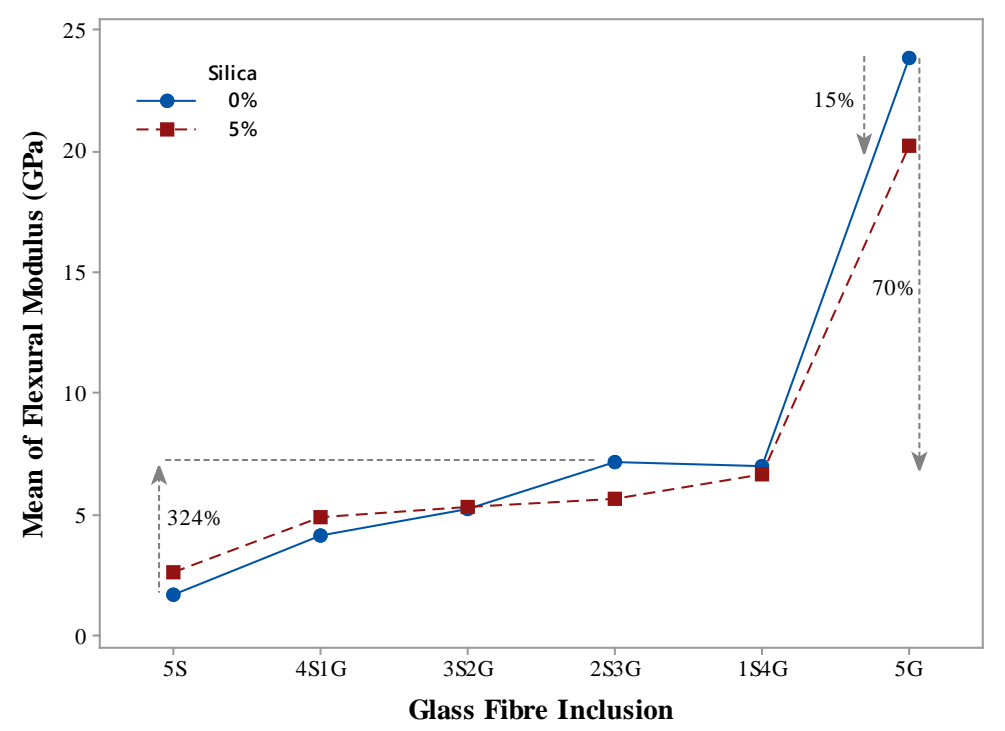

Figure 7. Interaction effect plot for mean flexural modulus.

\subsection{Fracture Surface Analysis}

The fracture analysis of the composites resulting from tensile and flexural tests was carried out using a scanning electron microscope. Among the different forms of fracture characteristics of the fibre-fibre composite are intralaminar fracture and interlaminar fibre fracture. Figure 8 shows the fracture surface of the glass fibre composites after the bending test. A fragile fracture containing some regions of failure by "fibre pull-out" is observed. The loss of matrix during the manufacturing process may have been the main responsible for the reduction of the mechanical properties of the material.

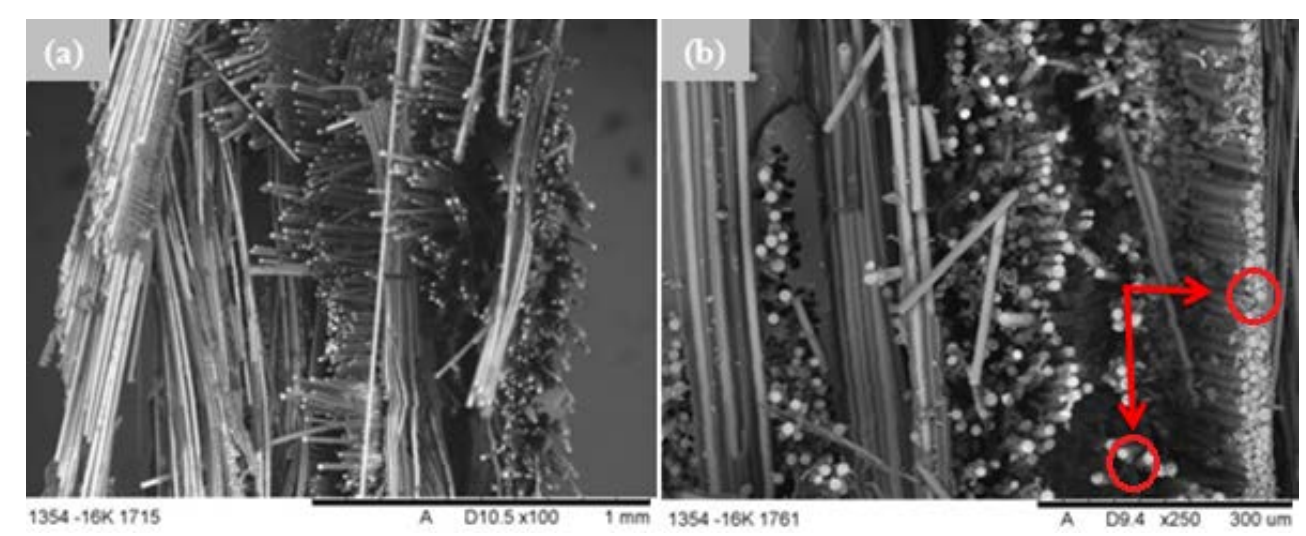

Figure 8. Fracture surface of the flexural test in glass fibre composites (5G).

Figure 9 shows the fracture section of composites reinforced with sisal fibres. The random distribution of fibres and the presence of macropores are observed, as well as the fibre pull-out failure characteristics. 


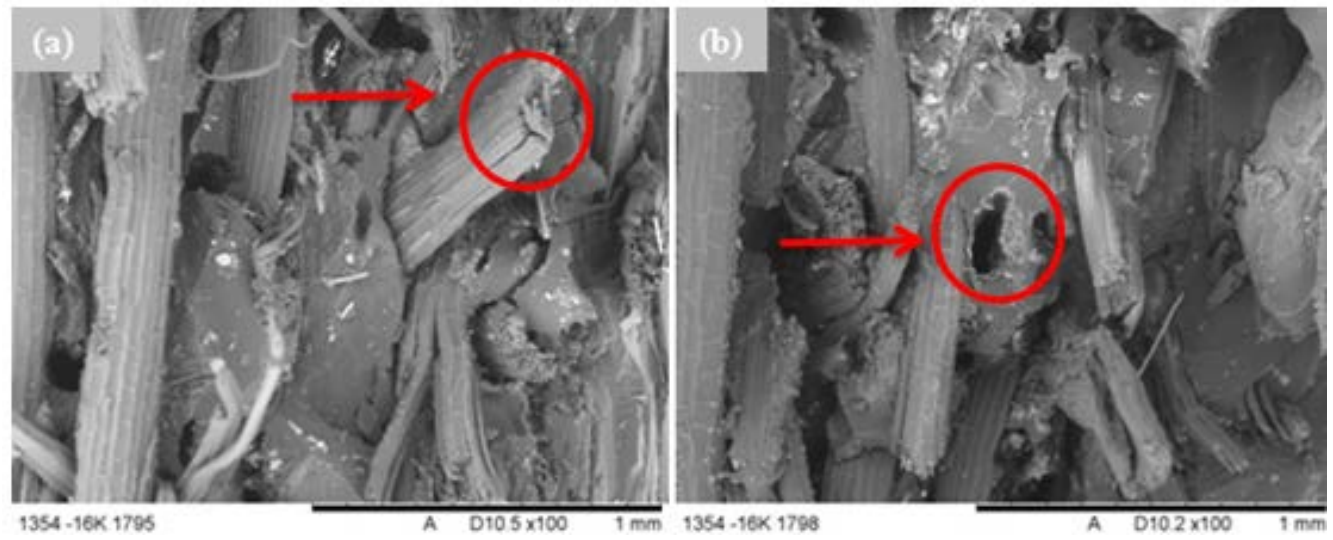

Figure 9. Fracture surface of the flexural test in sisal fibre composites (5S).

The delamination effect was more present in the hybrid composites due to the material difference and the mat structure (Figure 10). The structure of the sisal mat is formed by short and random fibres, while the glass fibre fabric has a cross-ply distribution. This variation along with the difference in the properties of each material leads to a combined behaviour at the time of fracture. Figure 10 shows that the characteristic fracture of sisal fibre is pull-out, while glass fibres break by fragile fracture.

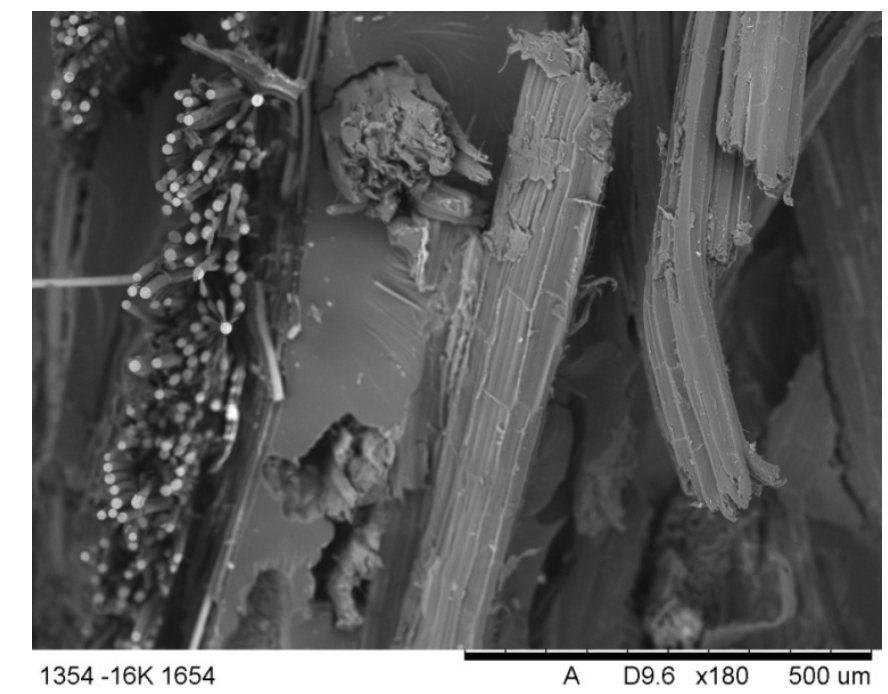

Figure 10. Fracture surface of the flexural test in hybrid composites (3S2G).

\section{CONCLUSIONS}

Hybridization of sisal/glass fibres and silica microparticles was assessed in this work. The main conclusions are described below:

- Replacement of sisal fibres by glass fibres led to significant effects on tensile strength, flexural strength, tensile modulus, flexural modulus and apparent density of the composites. Hybrid composites with higher number of glass fibre layers achieved higher mean values of tensile and flexural strength (348 MPa and 663.28 MPa, respectively), 
tensile and flexural modulus (22 GPa and 2.5 GPa, respectively) and apparent density $\left(2.02 \mathrm{~g} / \mathrm{cm}^{3}\right)$.

- Silica microparticles significantly affected the responses: flexural strength, tensile modulus and flexural modulus. The presence of silica particles improved the mechanical performance of the composites especially when considering a larger amount of sisal fibres, i.e. $5 \mathrm{~S}$ and $4 \mathrm{~S} 1 \mathrm{G}$ conditions.

- Finally, the 2S3G composites without silica particles achieved moderate strength and stiffness, being a promising alternative for secondary structural parts in projects with sustainable demands.

- The fracture analysis of the material presented as main types of fracture the pull-out effect and the delamination of the layers.

\section{ACKNOWLEDGMENTS}

The authors would like to thank CAPES, CNPq and FAPEMIG for the financial support.

\section{REFERENCES}

[1] Ashby, M.F., Bréchet, Y.J.M. Designing hybrid materials. Acta materialia, 51, n. 19, pp. 5801-5821, 2003.

[2] Callister, W.D. Materials Science and Engineering: An Introduction. 7th ed. New York: John Wiley \& Sons, 2007.

[3] Jarukumjorn, K., Suppakarn, N. Effect of glass fiber hybridization on properties of sisal fiber polypropylene. Composites: Part B, 40, pp. 623-627, 2009.

[4] Singh, B., Gupta, M., Verma, A. Mechanical behavior of particulate hybrid composite laminates as potential building materials. Construction and Building Materials, 9, pp. 39-44, 1995.

[5] Venkateshwaran, N., Elayaperumal, A., Sathiya, G.K. Prediction of tensile properties of hybridnaturalfiber composites. Composites Part B: Engineering, 43, n. 2, pp. 793-796, 2012.

[6] Nabi, S.D., Jog, J.P. Natural fiber polymer composites: a review. Advances in Polymer Technology, 18 (4), pp. 351-63, 1999.

[7] Mohan, T.P., Ramesh, M.K., Velmurugan, R. Thermal, mechanical and vibration characteristics of epoxy-clay nanocomposites. Journal Materials Science, 41, pp. 5915-25, 2006.

[8] Santana, P.R.T., Panzera, T.H., Freire, R.T.S., Christoforo, A.L. Apparent shear strength of hybrid glass fibre reinforced composite joints. Polymer Testing, 64, pp. 307-312, 2017.

[9] Cao, Y., Cameron, J. Flexural and shear properties of silica particle modified glass fiber reinforced epoxy composite. Journal of Reinforced Plastic and Composites, 25, pp. 347-59, 2006.

[10] Silva, L.J., Panzera, T.H., Velloso, V.R., Rubio, J.C.C., Christoforo, A.L., Scarpa, F. Statistical design of polymeric composites reinforced with banana fibres and silica microparticles. Journal of Composite Materials, 47, n. 10, pp. 1199-1210, 2012.

[11] Torres, R B., Santos, J. C., Panzera, T. H., Christoforo, A.L., Borges, P.H.R., Scarpa, F. Hybrid glass fibre reinforced composites containing silica and cement microparticles based on a design of experiment. Polymer Testing, pp. 87-93, 2016.

[12] Kickelbick, G. Introduction to hybrid materials. In: Kickelbick G, Editor. Hybrid mater synth charact appl. John Wiley \& Sons; 2007. 
[13] Wu, C.F.J., Hamada, M. Experiments: planning, analysis, and parameter design optimization, 2nd Edition, John Wiley \& Sons, 2000.

[14] ASTM D3039 / D3039M-14, Standard Test Method for Tensile Properties of Polymer Matrix Composite Materials, ASTM International, West Conshohocken, PA, 2014, www.astm.org.

[15] ASTM D790-15e2, Standard Test Methods for Flexural Properties of Unreinforced and Reinforced Plastics and Electrical Insulating Materials, ASTM International, West Conshohocken, PA, 2015, www.astm.org.

[16] BRITISH STANDARD. BS EN ISO 10545-3. Ceramic Tiles - Part 3: Determination of water absorption, apparent porosity, apparent relative density and bulk density. 1997.

[17] Montgomery, D.C. Design and Analysis of Experiments. 6 ed. Hoboken: John Wiley e Sons, pp. 643, 2005.

[18] Detomi, A.C.; Santos, R.M., Ribeiro Filho, S.L.M., Martuscelli, C.C., Panzera, T.H., Scarpa, F. Statistical effects of using ceramic particles in glass fibre reinforced composites. Materials \& Design, 55, pp. 463-470, 2013. 